\title{
Perceptual and conceptual priming in patients with dissociative identity disorder
}

\author{
RAFAËLE J. C. HUNTJENS, ALBERT POSTMA, ELLEN L. HAMAKER, \\ LIESBETH WOERTMAN, and ONNO VAN DER HART \\ Utrecht University, Utrecht, The Netherlands \\ and \\ MADELON PETERS \\ Maastricht University, Maastricht, The Netherlands
}

\begin{abstract}
The present study examined implicit memory transfer in patients with dissociative identity disorder (DID). To determine priming impairments in DID, we included both several perceptual priming tasks and a conceptual priming task using neutral material. We tested a large sample of DID patients $(n=31)$, in addition to 25 controls and 25 DID simulators, comparable on sex, age, and education. Controls replicated conceptual priming results of Vriezen, Moscovitch, and Bellos (1995) by showing that conceptual priming seems to require the formation of domain-specific semantic representations, denoting either sensory or functional object attributes. We extended a study performed by Schacter, Cooper, and Delaney (1990) by demonstrating priming for impossible objects using the sensitive priming index of response times. The simulators in the study were not able to simulate interidentity amnesia on the implicit memory tasks employed. Partly in contrast to participants in previous studies, DID patients showed evidence of perceptual priming as well as conceptual priming comparable to that of controls. DID patients thus displayed normal implicit memory performance.
\end{abstract}

Dissociative identity disorder (DID; formerly multiple personality disorder) is the most severe form of the dissociative disorders and is considered to be a pathological reaction to overwhelming, chronic childhood trauma (Spiegel $\&$ Cardeña, 1991). Particularly, sexual and physical abuse in association with emotional neglect in the first years of life have been found to correlate with dissociative symptoms in adulthood(Chu \& Dill, 1991; Draijer \& Langeland, 1999). DID is characterized by the presence of several distinct personality states, each of whom may be experienced as if it has a distinct personal history, self-image, and identity, including a separate name. In a review of 100 cases, Putnam, Guroff, Silberman, Barban, and Post (1986) reported a mode of three personality states or identities per patient. At least two identities recurrently take control of the person's behavior (American Psychiatric Association, 1994).

Episodes of interidentity amnesia, in which one identity claims amnesia for events experienced by other identities, are reported in $95 \%-100 \%$ of DID patients (Boon \& Drai-

A.P. was supported by a grant from the Netherlands Organization for Fundamental Research (NWO, 440-20-000). We thank Arnoud Arntz, Marcel van den Hout, Paul Knuijt, and Diane Pecher for their help in designing the study. We especially thank the patients who participated in the study and the clinicians for their help in gathering this large patient sample, as well as for their assistance in testing. Correspondence should be addressed to R. J. C. Huntjens, Department of Clinical Psychology, Faculty of Social Sciences, Utrecht University, and Research Institute for Psychology \& Health, P. O. Box 80.140, Utrecht 3508 TC, The Netherlands (e-mail: r.huntjens@fss.uu.nl). jer, 1993; Coons, Bowman, \& Milstein, 1988; Putnam et al., 1986; Ross et al., 1990; for a review see Gleaves, May, \& Cardeña, 2001). Several experimental studies have been performed on interidentity amnesia in DID (for reviews see Dorahy, 2001; Peters, Uyterlinde, Consemulder, \& Van der Hart, 1998), most of them focusing on alleged explicit memory impairments. In addition, clinical accounts have reported a lack of implicit memory transfer in DID, which is the expression of information without conscious or deliberate recollection(Schacter, 1987). Putnam (1995), for example, considers "fluctuations in skills, habits, and implicit knowledge" to be very common in DID (p. 593). These reports of implicit memory impairments contrast with the normal implicit memory performance usually found in brain-damaged amnesic patients (see, Roediger, 1990; Shimamura, 1986).

The procedure for testing implicit memory performance is as follows. In the study phase, a participant is shown a set of stimuli. In the subsequent test phase, the participant is tested for implicit transfer of that material. Positive priming is the facilitation or change in speed or accuracy with which participants perform a task using recently studied stimuli in comparison with unstudied stimuli (e.g., Schacter, 1987; Shimamura, 1986; Squire, 1986). With perceptual priming tasks, such as word fragment completion, the study material is reinstated in whole or in part in the test phase, and perceptual identification of the target or some aspect of it is required. With conceptual priming tasks, such as category generation, participants produce 
the studied item in response to test cues that are meaningfully or conceptually related to the studied item. According to the memory systems view, the two types of priming are mediated by different memory systems - that is, perceptual priming by the perceptual representation system (PRS) and conceptual priming by the semantic memory system (Schacter \& Tulving, 1994). According to the memory processing view, priming is based on the principle of transfer-appropriate processing - the overlap between study and test processing operations as either both data driven or both conceptually driven (Roediger \& McDermott, 1993; Roediger, Weldon, \& Challis, 1989). Combining and extending the memory system view and the memory processing view, Vriezen, Moscovitch, and Bellos (1995) have suggested that perceptual and conceptual priming may be linked to different sequential stages in information processing; that is, perceptual identification is followed by semantic analysis. Priming occurs only when study and test involve at least the same sequential stage of processing. Conceptual encoding of the stimulus material thus does enhance priming on a perceptual priming task, whereas perceptual encoding does not enhance priming on a conceptual priming task.

In DID, to our knowledge, only five experimental studies have examined implicit memory transfer between identities (Dick-Barnes, Nelson, \& Aine, 1987; Eich, Macaulay, Loewenstein, \& Dihle, 1997a, 1997b; Nissen, Ross, Willingham, Mackenzie, \& Schacter, 1988; Peters et al., 1998). These studies have obtained mixed results, which Nissen et al. and Eich et al. (1997b) have explained in terms of the influence of what they called identity-specific factors at the time of encoding and retrieval - that is, the identityspecific interpretation of material during encoding and the identity-specific selection of responses during retrieval. In terms of the identity-specific interpretation of material during encoding, evidence of amnesia in DID was obtained on conceptually driven tasks that make use of semantically rich materials that might be interpreted in different ways by different identities. In contrast, evidence of transfer between identities was obtained on data-driven tasks because this type of encoding leaves little room for identityspecific interpretation. In terms of identity-specific selection of responses during retrieval, transfer of information was obtained on tasks allowing for only a single response on each trial, like word fragments (e.g., $a-a-i n$, which can only be completed to form the word assassin). Evidence of amnesia was obtained on tasks allowing a wide range of responses (i.e., word stems that could be completed to form 10 or more words) whose selection could vary from one identity to the next.

One serious shortcoming of the previous studies of implicit memory in DID is that they have tested a very limited number of patients. Two were single-case studies (Dick-Barnes et al., 1987; Nissen et al., 1988), one study included 4 patients (Peters et al., 1998), one included 7 patients (Eich et al., 1997a), and one included 9 patients (Eich et al., 1997b). Moreover, only two studies have included control participants: Peters et al. used normal con- trols, whereas Eich et al. (1997a) included controls instructed to simulate DID. The inclusion of simulators is important given that the so-called sociocognitive model considers DID to be a syndrome of role enactment adopted by emotionally needy clients as a way of communicating their distress and gaining and maintaining the attention of therapists and others (Lilienfeld et al., 1999; Spanos, 1996).

The goal of the present study was to systematically test interidentity implicit memory transfer in DID while overcoming some of the methodological drawbacks of previous studies. We included a larger sample of female DID patients $(n=31)$ as well as a normal control group comparable on sex, mean age, and education level $(n=25)$. We made use of indirect memory tasks on which we expected malingering to be very difficult-through the use of speeded priming tasks and a 1-week interval between the encoding and retrieval phases in one task. Moreover, to ensure that malingering was not possible on the tasks employed, we included a control group instructed to simulate DID $(n=25)$. Following Silberman, Putnam, Weingartner, Braun, and Post (1985), the DID simulators were asked to make up an imaginary, "amnesic" identity and to "switch" upon request to this amnesic identity during the experiment. Also, they were given informative instructions about how to simulate interidentity amnesia in the memory tasks used.

Three implicit memory tasks were included to examine the explanation of implicit memory performance in DID suggested by Eich et al. (1997b) and Nissen et al. (1988). The influence of identity-specific interpretation of material during encoding was tested by contrasting a task using perceptual encoding with a task using conceptual encoding. The influence of identity-specific selection of responses during retrieval was tested in a task using perceptual encoding, contrasting trials with only 1 possible response in the retrieval phase with trials with 10 or more possible responses in the retrieval phase.

To explore perceptual priming in DID, we included a task determining priming of novel, visual objects. The task uses three-dimensional drawings that depict unfamiliar structures (for an example, see Schacter, Cooper, \& Valdiserri, 1992). Some of the drawings are structurally possible objects that can exist in the three-dimensional world. The others are impossible objects whose surfaces and edges contain ambiguities and inconsistencies that would prohibit them from existing as actual three-dimensional objects. Participants first performed a study phase that is considered to promote encoding of the three-dimensional object structure. In the test phase, they were given an indirect memory test in which studied and unstudied objects were flashed briefly on the screen, and the participants' task was to decide whether each object was possible or impossible. Priming effects in the object decision task are thought to depend on a subsystem of the perceptual representation system, the so-called structural-description memory system (Schacter \& Tulving, 1994). A structural description of an object refers to the mental representa- 
tion of relations among components of an object that specifies its global or three-dimensional form and structure in contrast to local or two-dimensional object features. Performance on the object decision task is facilitated by access to structural descriptions of target objects. Therefore, if a study task promotes the acquisition of a three-dimensional structural description of a target object, the availability of such knowledge at the time of test facilitates object decision performance. Priming, indicated by an increased proportion of accurate object decisions for studied objects in comparison with unstudied objects, has been observed only for possible objects and not for impossible objects, because participants are thought to have some difficulties forming mental images of structural impossibility (Cooper, Schacter, Ballesteros, \& Moore, 1992; Schacter, Cooper, \& Delaney, 1990; Schacter, Cooper, Delaney, Peterson, \& Tharan, 1991).

Conceptual priming was measured by a semantic classification procedure (see Vriezen et al., 1995, Experiments 1 and 6). Semantic memory contains factual informationboth concrete and abstract-about the world in the broadest sense, without an autobiographical reference (Schacter \& Tulving, 1994). Semantic domain-specific impairments have been observed in brain-damaged patients for either sensory or functional attributes of objects (Damasio, 1990; Patterson \& Hodges, 1995; Warrington \& Shallice, 1984). Sensory attributes describe physical (mainly visual) properties of an object such as color or shape. Functional attributes describe the function of an object-for example, the function of a wheelbarrow as an object used by people to carry material (Schacter, 1996). The task we used involves classifying visually presented words as quickly as possible with respect to some specified criterion. Priming is observed across different semantic classification tasks only if the study and test phases require access to information of the same semantic attributes-that is, either of sensory attributes or of functional attributes (Vriezen et al., 1995). In the study phase, subjects responded to a question pertaining to sensory attributes (a question about an item's overall size in the real world). In the test phase, they had to respond to a second question pertaining to sensory attributes (about an item's relative dimensions) and a question pertaining to functional attributes (whether an item is man-made or not). The sensory attribute question in the test phase is denoted the related question, and the functional attribute question is denoted the unrelated question.

Finally, a word stem completion task was added to investigate the influence of identity-specific selection of responses during retrieval. The task was a Dutch equivalent of tasks that are frequently referred to in the literature on amnesic patients as the "juice task" and the "motel task" (Graf, Squire, \& Mandler, 1984; Squire, Shimamura, \& Graf, 1987). In the task used, half of the word stems could only be completed with one word or a variation of the word (e.g., jui with juice or juicy as completion). These were designated the single completion word stems. The other half had 10 or more completions (i.e., motel or motive for mot) and were denoted the multiple completion word stems.
In the object decision task we used a 1-week interval between the study and test phases, instead of the test phase immediately following the study phase, as in the procedure employed by Cooper et al. (1992) and Schacter et al. (1990; Schacter et al., 1991; Schacter et al., 1992). Also, in all three tasks, we instructed participants to react as fast as possible and repeated this instruction after the practice trials to ensure high-speed performance. Both measures were taken to prevent malingering by decreasing the explicit memory traces of the studied objects available for participants in the test phase. We expected these measures as well as the encoding instructions in the implicit task to result in the absence of explicit recollection of stimulus material in the test phase. Consequently, we expected simulators to perform at about the same level as controls. If explicit recollection of the studied items was still available and applicable, simulators might use their recollection of studied items to decrease the proportion of correct responses and to slow down their responses to studied items.

Controls were expected to reveal a priming effect on the possible objects in the perceptual priming task and on the related question in the conceptual priming task, and no priming effect on the impossible objects and the unrelated question. They also were expected to show evidence of priming on both single and multiple completion word stems. Following Eich et al. (1997b) and Nissen et al. (1988), DID patients were expected to perform equally to controls on the perceptual priming task but to show evidence of interidentity amnesia on both the related and the unrelated questions of the conceptual priming task due to the task's conceptual encoding in the study phase. Evidence of transfer was expected on the single completions, and evidence of interidentity amnesia was expected on the multiple completions in the word stem completion task.

\section{METHOD}

\section{Participants}

Thirty-one female DID patients participated in the study. Patients were recruited with the help of clinicians in The Netherlands and Belgium. To be eligible for participation, patients had to meet the DSM-IV (American Psychiatric Association, 1994) criteria and the criteria of the Structured Clinical Interview for DSM-IV Dissociative Disorders (SCID-D), a semistructured interview used to diagnose the DSM-IV dissociative disorders (Boon \& Draijer, 1994; Steinberg, 1993). The mean number of years since diagnosis of DID for patients was 4.42 years (range 3 months to 11 years), and DID was always the main reason for patients to be in treatment. Participants were informed that the aim of the study was to understand more about the memory problems often reported by DID patients. Patients self-selected two identities that would participate in the experiment. Borrowing terms prevalent in DID clinical practice, we described conditions for participation as follows: (1) At least one of the identities is completely amnesic for the events experienced by the other participating identity during the experiment; (2) these two identities are able to perform the tasks without interference from other identities; (3) these two identities are able to perform the tasks without spontaneous switches to other identities; (4) the patient is able to switch between these two identities on request. The selected identities could be either female or male.

In addition, 50 female controls participated. Groups were comparable on age and education (Table 1). Control participants did not report any relevant memory, visual, or attentional problems or psy- 
Table 1

Participant Characteristics for the Three Groups: DID Patients, Controls, and Simulators

\begin{tabular}{lcccc}
\hline \multicolumn{1}{c}{ Group } & Age (Years) & Education & DES & CEQ \\
\hline DID patients $(n=31)$ & & & & \\
$\quad M$ & 38.48 & 5.39 & - & - \\
$\quad S D$ & 8.68 & 1.20 & - & - \\
Controls $(n=25)$ & & & & \\
$\quad M$ & 37.72 & 5.88 & 6.31 & 5.48 \\
$S D$ & 11.29 & 1.13 & 4.10 & 3.24 \\
Simulators $(n=25)$ & & & & \\
$\quad M$ & 32.48 & 5.84 & 6.54 & 4.20 \\
$S D$ & 10.31 & 1.14 & 3.93 & 2.58 \\
\hline
\end{tabular}

Note-Education was assessed on a scale from 1 (low) to 7 (high) (Verhage, 1964); DES, Dissociative Experiences Scale (score range 0-100); CEQ, Creative Experiences Questionnaire (score range 0-25).

chiatric disorders. Control participants were divided into two groups, the controls and the simulators. Simulators were instructed to imitate DID. They were shown a documentary about a DID patient and were given additional written information about DID. They were subsequently asked to make up an imaginary, amnesic identity and come up with detailed characteristics of this identity. Following Silberman et al. (1985), they were given a 17-item data sheet for the identity on which they were asked to assign name, age, sex, physical description, personal history, and personality style. Examination of the completed data sheets confirmed that participants had invested considerable effort in inventing an identity. Finally, they were asked to practice during the week preceding the experiment switching to their new identity and taking on its state of mind.

Both the controls and the simulators completed the Dissociative Experiences Scale (DES; Carlson \& Putnam, 1993) and the Creative Experiences Questionnaire (CEQ; Merckelbach, Muris, Schmidt, Rassin, \& Horselenberg, 1998) (Table 1). The DES is a 28-item selfreport questionnaire with scores ranging from 0 to 100 . Scores above 20 or, more conservatively, above 30 , are thought to be indicative of pathological dissociation. The CEQ is a 25 -item self-report questionnaire with scores ranging from 0 to 25 . Scores are thought to be indicative of fantasy proneness - that is, the inclination to be immersed in daydreams and fantasies. The controls and the simulators did not differ significantly on DES scores or CEQ scores. Neither controls nor simulators showed pathological levels of dissociation as measured by the DES. Written informed consent was obtained from all participants prior to participation.

\section{Design}

Participants were tested in two sessions separated by a 1-week interval. Because of illness, 5 participants were tested after a longer interval: one patient after 9 days, 1 control subject after 8 and 1 after 14 days, and 1 simulator after 10 and 1 after 12 days. In the first session, participants initially completed the study and test phases of the word stem completion task. Subsequently, they performed the study phase of the perceptual encoding task. In the second session, they performed the test phase of the perceptual encoding task, after which they completed the study and test phases of the conceptual encoding task. Participants performed the priming tasks as part of a larger study on reported memory impairments in DID (Huntjens, Postma, Peters, Woertman, \& Van der Hart, 2001). There was no overlap in study material between tasks. The encoding and retrieval phases of all of the studies described were performed by different identities, with the retrieval phase performed by an identity subjectively reporting complete amnesia for the encoding phase. At the beginning of each retrieval phase, the identity reporting amnesia was asked if she knew anything about the encoding phase performed by the other participating identity and/or of the material presented in the encod- ing phase. She was asked to answer with "yes" or "no." If she answered with "yes," she was asked what she knew exactly (e.g., instructions, stimulus material).

In the laboratory, many DID patients can alternate or "switch" between identities on demand, although this is not always under their control. Switches typically occur in seconds to minutes and are manifested by changes in facial expression, quality and quantity of speech, attentional focus, reported cognitive capacities, and affect (Putnam, 1997). As mentioned in the conditions for participation, patients in this study were able to switch between the two participating identities on request and were able to perform the tasks without spontaneous switches to other identities. Patients made the switch to and from the participating identities at the beginning and end of both sessions and between participating identities before each test phase. The transition was initiated by asking the patient to let an identity "come forward" and take control of the patient's consciousness and behavior. Also, the patient was asked to let the other participating identity "step back," thereby moving out of consciousness. The switching process was assisted either by the patients' own clinician or by one of the authors (R.H. or O.V.). The switching process was always accomplished in less than $2 \mathrm{~min}$. Controls performed the tasks without switching; instead, they had a 2-min break to keep the length of procedures equal between groups. Simulators performed the study phase of all three tasks in their normal identity state and the test phase in their imagined amnesic identity.

\section{Materials}

Line drawings representing objects were used in the perceptual priming task. Like all stimuli in this study, they had a neutral affective meaning. Object drawings were obtained from Schacter et al. (1990). Four sets of drawings were constructed on the basis of a pilot study in which 35 psychology students (mean age $=21.41$ years, $S D=2.99$ ) were shown object drawings and were asked to classify each object as possible or impossible. On the basis of the participants' scores, four sets of drawings were assembled, two sets depicting possible objects and two sets depicting impossible objects. The two sets depicting possible objects were matched according to proportioncorrect object decisions $[t(34)=0.35, p=.73]$ and mean response time $[t(34)=-1.03, p=.31]$, one to function as a studied set and one to function as an unstudied set. Because it did not prove possible to construct sets of 10 drawings of impossible objects that did not differ in mean proportion-correct object decisions, sets of 9 drawings were used. These were also matched according to proportioncorrect object decisions $[t(34)=-0.78, p=.44]$ and mean response time $[t(34)=0.02, p=.98]$. The measurement of response times was not part of the original studies developed by Schacter et al. (1992); response time was used as an additional index of priming.

For the conceptual priming task, four sets of 16 Dutch words representing objects were assembled. Words in each of two sets were matched with respect to the response times of 38 pilot participants to the question "Is it taller than it is wide?" (the dimension question). These matched sets are called Set A and Set C. Words in each of the other two sets were matched with respect to the response times of the pilot participants to the question "Is it man-made?" (the manmade question). These matched sets are called Set B and Set D. In a second pilot study $(n=20)$, some adjustments were made to the sets, and in a third pilot study $(n=35$; mean age $=21.41$ years, $S D=2.99$ ), the final sets were tested for mean response times. The difference in mean response time between Sets $\mathrm{A}$ and $\mathrm{C}$ was nonsignificant $\left[F(1,33)=3.05, M S_{\mathrm{e}}=1,167.02, p=.09\right]$. Also, the difference in mean response time between Sets B and D was nonsignificant $\left[F(1,33)=0.02, M S_{\mathrm{e}}=2,066.39, p=.89\right]$. The pilot study was also used to test order of questions. Half of the participants $(n=$ 18) answered the dimension question first and the other half ( $n=$ 17) answered the man-made question first. No significant effects of order were found. Subsequently, three lists were made, each for a different classification task. List 1 was used in the study phase and 
consisted of Set A and Set B. List 2 was used for the related categorization question and consisted of Set A and Set C, and List 3 was used for the unrelated categorization question and consisted of Set B and Set D. Three additional lists of four words served as practice items preceding Lists 1, 2, and 3.

For the word stem completion task, four sets of word stems were constructed on the basis of a pilot study in which 33 psychology students (mean age $=21.48$ years, $S D=3.01$ ) served as participants. They were shown 40 three-letter word stems sequentially and were asked to say aloud the first word that popped into mind that would complete the word stem. On the basis of the proportion of word stem completions and response times, two sets of single-completion word stems were constructed, one to function as a studied set and one as an unstudied set. Because it did not prove possible to construct sets of 10 word stems that did not differ in priming measures, we made sets of 9 word stems. These single-completion word stem sets did not differ in mean correct completions $[t(32)=-1.11, p=.28]$, nor did they differ in mean response time $[t(32)=0.82, p=.42]$. Two sets of 10 multiple-completion word stems were composed that did not differ in mean correct completions $[t(32)=-0.82, p=.42]$ nor in mean response time $[t(32)=-.51, p=.61]$.

\section{Procedure}

In the perceptual priming task, patients were informed in Identity State 1 that they would see complicated drawings of objects and that the experiment was concerned with short-term memory for objects. Patients were instructed to study each object for $5 \mathrm{sec}$ and then to decide how they would divide it in two equal halves (i.e., to look for the plane of symmetry). They were instructed to study the entire object, not just parts of it. After $5 \mathrm{sec}$, the drawing disappeared and participants had to indicate with their hands how they would divide the object in two equal halves. After the presentation of five practice items, participants were shown a set of possible and a set of impossible object drawings, all presented in a different random order for each participant. The symmetry task was meant to ensure the encoding of the three-dimensional object structure.

In the second session, patients were told that they would be exposed to a series of briefly displayed drawings. They were informed that some of the drawings represented valid, possible three-dimensional objects that could exist in the real world, whereas other drawings represented impossible objects that could not exist as actual objects in the real world. It was explained that their task was to decide whether each object was possible or impossible. One practice object of each type was then shown. They were informed that all possible objects must have volume and be solid, need not be familiar, could be made out of stone or clay, and that they could not see through them. Participants were instructed to respond by pressing the "M" key in response to possible objects and the " $Z$ " key in response to impossible objects. They were asked to do this as quickly and as accurately as possible. The object decision task then began with the presentation of 10 practice items. Subsequently, participants were informed that the critical test would now begin and the instruction to react as fast as possible was repeated. The critical test consisted of the sequential presentation of 40 drawings in a different random order for each participant. Each drawing was presented for $100 \mathrm{msec}$, preceded by a fixation point for $500 \mathrm{msec}$ and followed by a dark screen. The intertrial interval was $2,000 \mathrm{msec}$. Before switching to their amnesic identity in Session 2, simulators were told that they would be asked to perform a task that would involve both drawings they had already seen in Session 1 and unstudied, new drawings. They were instructed to pretend that they did not know that their normal identity had performed the object-dividing task and thus to pretend to have no memory of the drawings. Subsequently, they were given 2 min to take on their amnesic identity's state of mind.

In the conceptual priming task, participants were informed that the purpose of the experiment was to see how quickly people have access to knowledge about words. Patients were first instructed to categorize objects as fast as possible by overall size ("Is it larger than a television set?") in Identity State 1 . They performed four practice items on which they received feedback, after which List 1 was presented. They were instructed to respond by pressing the "M" key if their answer was "yes" and the "Z" key if their answer was "no." Each word was shown until a response was made. Once a response was made, the word was removed and the screen remained blank for 2,000 msec; then the next word appeared. Subsequently, patients performed the related categorization trials (the dimension question) in Identity 2 . They again started with four practice items, and then they were shown List 2. Finally, patients performed the unrelated categorization trials (the man-made question), also in Identity 2. They again started with four practice items, followed by List 3. Simulators performed the size categorization question in their normal identity state. They performed the related dimension question and the unrelated man-made question after having switched to their imagined amnesic identity. Before being given 2 min to take on their amnesic identity's state of mind, they were told that they would be asked to answer two similar questions with both words they had already seen and unstudied words. They were instructed to pretend that they did not know that their normal identity had performed the size question and thus to pretend to have no memory of the words. They were also instructed to respond as fast as possible but not faster to words they had seen in their normal identity state.

In the study phase of the word stem completion task, 23 nouns were presented sequentially to the patient's Identity 1 in random order on a computer screen. Patients were asked to count the number of letters that either had a "stick" (e.g., "b" or "f ") or a "tail" (e.g., "g" or " $\mathrm{j}$ "). Each word was shown for $2 \mathrm{sec}$. Then, a question mark appeared on the screen and participants had a maximum of $10 \mathrm{sec}$ to press the correct key. This task was meant to ensure that patients encoded the words without being told that the words would be referred to in a stem completion phase later on. The 23 words were the possible completions of one set of single completions and one set of multiple completions together with four items to prevent primacy and recency effects. Then after four practice trials, all 38 word stems of the studied and unstudied single- and multiple-completion sets were presented to Identity 2 in random order without making reference to having been studied by Identity 1 . The procedure in this phase was the same as the procedure followed in the pilot study. The participants' response time was determined using a voicekey. The experimenter scored their verbal response. Participants were allowed a maximum of $3 \mathrm{sec}$ to provide an answer. Simulators were told that they would now be asked to perform a word stem task in which half of the stems could be completed with a word they had just studied. They were instructed to pretend that they did not know their normal identity had performed the study phase and thus had no memory of the words.

\section{Results}

Of the 31 DID patients tested, a number of patients reported some explicit knowledge of the study phase in the test phase-namely 6 patients in the perceptual priming task, 2 patients in the conceptual priming task, and 5 patients in the word stem completion task. These patients were left out of the analyses. Data of 1 other patient in the perceptual priming task, 3 patients in the conceptual priming task, and 2 patients in the word stem completion task were not included because emotional problems unrelated to the study interfered with the testing. Data of 2 additional patients in the word stem completion task were not included because of software errors. The results described therefore pertain to 24 DID patients in the perceptual priming task, 26 in the conceptual priming task, and 22 in the word stem completion task. 
Table 2

Perceptual Priming: Mean Proportion-Correct Object Decisions for Possible and Impossible Objects as a Function of Group

\begin{tabular}{lccc}
\hline & \multicolumn{3}{c}{ Group } \\
\cline { 2 - 4 } Object Type & DID Patients & Controls & Simulators \\
\hline Possible Objects & & & \\
$\quad$ Studied & & .85 & .85 \\
$\quad M$ & .75 & .18 & .13 \\
$\quad S D$ & .17 & & \\
Unstudied & & .65 & .68 \\
$\quad M$ & .64 & .15 & .17 \\
$S D$ & .21 & & \\
Impossible Objects & & .74 & .80 \\
Studied & & .15 & .18 \\
$M$ & .66 & & \\
$S D$ & .18 & .67 & .76 \\
Unstudied & & .21 & .16 \\
$\quad M$ & .66 & & \\
$S D$ & .18 & &
\end{tabular}

In the analyses reported, response times more than $2 S D$ from the mean per participant per word set were excluded. However, because it could be argued that removal of scores more than $2 S D$ from the mean excludes extreme scores, reducing the mean response times for studied words of simulators in particular, all analyses were repeated with the inclusion of response times that were more than $2 S D$ from the mean. These analyses, however, yielded equivalent priming results for simulators.

\section{Perceptual Priming}

Mean proportion-correct object decisions and mean response times for correct object decisions for possible and impossible objects are presented in Tables 2 and 3. Consider first the mean proportion-correct object decisions for possible objects. A $2 \times 3$ object repetition (studied vs. unstudied) $\times$ diagnosis group (patients vs. controls vs. simulators) analysis of variance (ANOVA) revealed that there was a significant repetition effect $[F(1,71)=62.95$, $\left.M S_{\mathrm{e}}=0.015, p<.001\right]$. The object repetition $\times$ diagnosis group interaction proved nonsignificant $[F(2,71)=$ $\left.1.78, M S_{\mathrm{e}}=0.015, p=.18\right]$, indicating that the repetition effect did not differ between the diagnosis groups. There was no significant main effect of diagnosis $[F(2,71)=1.39$, $\left.M S_{\mathrm{e}}=0.022, p=.26\right]$. For the mean response times for possible objects, a corresponding ANOVA revealed that there was a significant repetition effect $[F(1,71)=6.25$, $\left.M S_{\mathrm{e}}=80,182.61, p=.015\right]$. The object repetition $\times$ diagnosis group interaction again proved nonsignificant $\left[F(2,71)=0.94, M S_{\mathrm{e}}=80,182.61, p=.40\right]$, indicating that the repetition effect did not differ between the diagnosis groups. The main effect of diagnosis was not significant either $\left[F(2,71)=2.84, M S_{\mathrm{e}}=196,851.46, p=.065\right]$.

For the mean proportion-correct object decisions for impossible objects, the corresponding ANOVA showed that there was no significant repetition effect $[F(1,71)=$ $\left.2.23, M S_{\mathrm{e}}=0.018, p=.14\right]$. The object repetition $\times$ diagnosis group interaction was not significant either $[F(2,71)=$ $\left.0.70, M S_{\mathrm{e}}=0.018, p=.50\right]$, indicating that this was the case for all the diagnosis groups. There was, however, a significant main effect of diagnosis $[F(2,71)=3.90$, $\left.M S_{\mathrm{e}}=0.022, p=.025\right]$. Tukey's honestly significant difference (HSD) pairwise comparison procedures indicated that patients had significantly smaller proportions of correct decisions than did simulators $(p=.020)$. Patients did not score differently from controls $(p=.60)$. Neither did simulators' proportion of correct decisions differ from controls' $(p=.18)$. For mean response times for impossible objects, the corresponding ANOVA revealed that there was a significant repetition effect $[F(1,71)=4.81$, $\left.M S_{\mathrm{e}}=84,520.65, p=.032\right]$. The object repetition $\times$ diagnosis group interaction was not significant $[F(2,71)=$ $\left.0.52, M S_{\mathrm{e}}=84,520.65, p=.60\right]$, indicating that the repetition effect did not differ between the diagnosis groups. There was no significant main effect of diagnosis $\left[F(2,71)=2.11, M S_{\mathrm{e}}=279,583.23, p=.13\right]$.

\section{Conceptual Priming}

Proportion-incorrect responses on the related and unrelated questions was very low $(M=.039, S D=.041)$. No main effect or interaction reached significance. As in the Vriezen et al. (1995) study, this measure could not be used as an index of priming. Mean response times for the related and unrelated trial condition are presented in Table 4 . We excluded incorrect responses. On the related question, a $2 \times$ 3 word repetition (studied vs. unstudied) $\times$ diagnosis group (patients vs. controls vs. simulators) ANOVA showed that there was a significant repetition effect $[F(1,73)=23.09$, $\left.M S_{\mathrm{e}}=13,709.66, p<.001\right]$. The word repetition $\times$ diagnosis group interaction was not significant $[F(2,73)=1.43$, $\left.M S_{\mathrm{e}}=13,709.66, p=.25\right]$, indicating that the repetition effect did not differ between the diagnosis groups. There was a significant main effect of diagnosis $[F(2,73)=14.35$, $\left.M S_{\mathrm{e}}=154,835.29, p<.001\right]$. Tukey's HSD pairwise comparison procedures indicated that patients reacted significantly more slowly than controls $(p<.001)$ and more

Table 3

Perceptual Priming: Mean Response Times (in Milliseconds) for Correct Object Decisions for Possible and Impossible Objects as a Function of Group

\begin{tabular}{lccc}
\hline & \multicolumn{3}{c}{ Group } \\
\cline { 2 - 4 } Object Type & DID Patients & Controls & Simulators \\
\hline Possible Objects & & & \\
Studied & & & \\
$M$ & 1,098 & 295 & 930 \\
$S D$ & 413 & & 603 \\
Unstudied & & 977 & 970 \\
$M$ & 1,295 & 272 & 417 \\
$\quad S D$ & 752 & & \\
Impossible Objects & & 956 & 990 \\
Studied & 1,209 & 271 & 497 \\
$M$ & 643 & & \\
$S D$ & & 1,085 & 1,027 \\
Unstudied & 1,359 & 533 & 725 \\
$\quad M$ & 628 & &
\end{tabular}


Table 4

Conceptual Priming: Mean Response Times (in Milliseconds) for Correct Responses for Semantically Related and Unrelated Classification Questions as a Function of Group

\begin{tabular}{lccc}
\hline & \multicolumn{3}{c}{ Group } \\
\cline { 2 - 4 } Question Type & DID Patients & Controls & Simulators \\
\hline Related & & & \\
Studied & & & \\
$M$ & 1,346 & 104 & 333 \\
$S D$ & 534 & 887 & 1,024 \\
Unstudied & & 147 & 326 \\
$M$ & 1,471 & & \\
$S D$ & 647 & 806 & 888 \\
Unrelated & & 179 & 283 \\
Studied & 1,080 & & \\
$M$ & 387 & 811 & 876 \\
$S D$ & & 153 & 243 \\
Unstudied & 1,100 & & \\
$M$ & 539 & &
\end{tabular}

slowly than simulators $(p=.001)$. Simulators' response times did not differ from controls' $(p=.31)$.

On the unrelated question, the corresponding ANOVA revealed that there was no significant repetition effect $\left[F(1,73)=0.04, M S_{\mathrm{e}}=19,314.72, p=.85\right]$. The word repetition $X$ diagnosis group interaction was not significant $\left[F(2,73)=0.17, M S_{\mathrm{e}}=19,314.72, p=.85\right]$, indicating that this was the case for all of the diagnosis groups. There was a significant main effect for diagnosis $[F(2,73)=$ $\left.5.61, M S_{\mathrm{e}}=97,674.23, p=.005\right]$. Tukey's HSD pairwise comparison procedures indicated that patients reacted significantly more slowly than controls $(p=.005)$. The difference between DID patients and simulators was marginally significant $(p=.051)$. Simulators' response times did not differ from controls' $(p=.69)$.

\section{Word Stem Completion With One or More Possible Responses}

For the single-completionstems, the proportions correctly completed used stems for studied and unstudied word stems were calculated. For the multiple-completionstems, the proportion of correctly completed word stems was calculated as the proportion word stems completed to a studied word or another correct completion. For single- and multiple-word stems, the mean studied and unstudied response times were calculated as the mean response time of the word stems that were correctly completed. Mean proportions of correctly completed word stems and mean response times are presented in Tables 5 and 6 . Consider first the proportions of correctly completed single completion word stems. A repeated measures analysis revealed a significant word repetition effect $\left[F(1,69)=63.01, M S_{\mathrm{e}}=\right.$ $0.013, p<.001]$. The interaction of word repetition $\times$ diagnosis, however, did not prove significant $[F(2,69)=$ $\left.0.82, M S_{\mathrm{e}}=0.013, p=.45\right]$, indicating that the repetition effect did not differ between diagnosis groups. There was a significant main effect of diagnosis $[F(2,69)=5.24$, $\left.M S_{\mathrm{e}}=0.032, p=.008\right]$. Pairwise comparisons indicated that patients completed significantly fewer studied and unstudied word stems than did controls ( $p=.009)$ or simulators $(p=.038)$. Simulators did not differ from controls $(p=.84)$. For single-completion mean response times, a repeated measures analysis revealed a significant word repetition effect $\left[F(1,69)=15.62, M S_{\mathrm{e}}=59,429.22, p<\right.$ $.001]$. The interaction of word repetition $\times$ diagnosis was not significant $\left[F(2,69)=1.18, M S_{\mathrm{e}}=59,429.22, p=\right.$ .31 , indicating that the repetition effect did not differ between diagnosis groups. There was a significant main effect of diagnosis $\left[F(2,69)=4.31, M S_{\mathrm{e}}=80,569.46, p=\right.$ .017]. Pairwise comparisons indicated that response times of patients were significantly increased compared with those of controls ( $p=.014)$. Simulators did not differ significantly in response time from patients $(p=.55)$. The difference in response time between simulators and controls also did not reach significance $(p=.15)$.

For proportions of correctly completed multiplecompletion word stems, a repeated measures analysis revealed no significant word repetition effect $[F(1,69)=$ $\left.0.02, M S_{\mathrm{e}}=0.0062, p=.89\right]$. The interaction between word repetition and diagnosis was not significant either $\left[F(2,69)=1.04, M S_{\mathrm{e}}=0.0062, p=.36\right]$. There was no significant main effect of diagnosis $[F(2,69)=2.50$, $\left.M S_{\mathrm{e}}=0.0071, p=.09\right]$. Additionally, $t$ tests were performed to compare multiple-completion proportions of word stems completed to a studied word to a chance rate of 10 . This chance level of .10 reflects the 10 or more possible completions in this set of word stems (e.g., Nissen et al., 1988). The mean proportions of studied word stems that were completed to a studied word (i.e., excluding word stems completed to another correct completion) indicated evidence of repetition $(M=.26, S D=.14$ for controls; $M=.18, S D=.12$ for patients; $M=.17, S D=.094$ for simulators). $T$ tests comparing the scores with the chance proportion of .10 indicated evidence of repetition in all participants-patients $[t(21)=3.25, p=.004]$, controls $[t(24)=5.91, p<.001]$, and simulators $[t(24)=3.85$,

Table 5

Word Stem Completion: Mean Proportion of Correct Single- and Multiple-Completion Word Stems as a Function of Group

\begin{tabular}{llll}
\hline & \multicolumn{3}{c}{ Group } \\
\cline { 2 - 3 } Word Stem Type & DID Patients & Controls & Simulators \\
\hline
\end{tabular}

Single-Completion Stems

Studied

$M$

$S D$

.67

.23

.84

Unstudied

$M$

$S D$

.52

.26

.66

.18

Multiple-Completion Stems

Studied

M

$S D$

.89

.12

.92

Unstudied

M

$S D$
.08

.92

.07
.16

.79

.16

.66

.92

.09

.94

.07 
Table 6

Word Stem Completion: Mean Response Times (in Milliseconds) for Correctly Completed Single- and Multiple-Completion Word Stems as a Function of Group

\begin{tabular}{lrrr}
\hline & \multicolumn{3}{c}{ Group } \\
\cline { 2 - 4 } Word Stem Type & DID Patients & Controls & Simulators \\
\hline Single-Completion Stems & & & \\
$\quad$ Studied & & & \\
$\quad M$ & 1,234 & 985 & 1,206 \\
$\quad S D$ & 354 & 218 & 394 \\
$\quad$ Unstudied & & & \\
$\quad M$ & 1,428 & 1,199 & 1,281 \\
$\quad S D$ & 422 & 295 & 280 \\
Multiple-Completion Stems & & & \\
$\quad$ Studied & & & \\
$\quad M$ & 1,304 & 958 & 1,122 \\
$S D$ & 348 & 151 & 251 \\
$\quad$ Unstudied & & & \\
$M$ & 1,286 & 1,051 & 1,242 \\
$S D$ & 354 & 192 & 324 \\
\hline
\end{tabular}

$p=.001]$. An ANOVA revealed that diagnosis groups differed significantly in the proportion of studied word stems completed to a studied word $\left[F(2,69)=4.19, M S_{\mathrm{e}}=\right.$ $0.014, p=.019]$. Pairwise comparisons revealed that simulators scored significantly lower than controls $(p=$ .026). Although patients also scored lower than controls, this did not reach significance $(p=.066)$. Patients did not differ from simulators $(p=.96)$. A repeated measures analysis on mean studied and unstudied multiple-completion response times revealed a significant repetition effect $\left[F(1,69)=5.85, M S_{\mathrm{e}}=26,001.91, p=.018\right]$. Although response times for patients were equivalent for studied and unstudied words, the interaction of word repetition and diagnosis proved nonsignificant $\left[F(2,69)=2.35, M S_{\mathrm{e}}=\right.$ $26,001.91, p=.10]$. There was a significant main effect of diagnosis $\left[F(2,69)=7.91, M S_{\mathrm{e}}=64,137.09, p=.001\right]$. Pairwise comparisons indicated that patients had significantly longer response times than controls $(p=.001)$. The difference between simulators and controls also was significant $(p=.041)$; patients did not differ from simulators $(p=.29)$.

In summary, although participants did not complete more studied than unstudied multiple-completion word stems with a correct completion in the word stem completion task, they did complete more multiple-completion stems with studied words than would be expected on a chance level of $10 \%$. Also, they showed decreased response times to studied words relative to unstudied word stems. On the single-completion stems, priming was also evident from the increased proportion of correct completions for studied words and the decreased response times of studied words in comparison with unstudied words. Participants thus showed clear evidence of priming on both types of word stems.

\section{DISCUSSION}

The present study aimed to assess the transfer of implicit memory between identities in DID. In agreement with studies performed by Eich et al. (1997a, 1997b) and Nissen et al. (1988), we obtained evidence of priming for DID patients comparable to that of controls on a data-driven task (the perceptual encoding task) and on a task allowing for only a single response on each trial (word stem completion task). Moreover, and in contrast to studies by Eich et al. (1997b), Nissen et al., and Peters et al. (1998), we also observed priming effects on a conceptually driven task and a task allowing for a range of responses (word stem completion task). Patients thus showed evidence of transfer of information between identities on all implicit memory tasks employed. It should be noted that despite not differing from controls with respect to implicit memory effects, patients did show a generally impaired performance on the conceptual encoding task and the word stem completion task, as is evident from their significantly longer response times to both studied and unstudied items. They also produced fewer correct word stem completions. The DID patients' less efficient and slower performance could have been the result of their having fewer processing resources available for memory tasks because of an emotional preoccupation, as also reported in depressed and anxious patients (Baddeley, Wilson, \& Watts, 1995).

It can be argued that interidentity amnesia was not expected in the first place on the word stem completion task with multiple completions due to its data-driven encoding (i.e., the counting of "sticks" and "tails"). However, both the related and unrelated conceptually driven tasks also allowed for multiple-although only two-response alternatives while requiring conceptual encoding of an object's sensory and functional attributes. Although the identityspecific interpretation of material at the time of encoding and the identity-specific selection of responses during retrieval has been considered the crucial distinctive factor in finding interidentity amnesia in DID (Eich et al., 1997b; Nissen et al., 1988), we did not obtain evidence for this. At the perceptual stage of information processing, the formation of new structural object representations and the activation of existing word representations in the encoding phase appears to extend to the retrieval phase performed by another identity in DID patients. Similarly, at the conceptual stage, the representation of objects' sensory attribute information seems to transfer to another identity, indicating that very specific encoding and retrieval operations persist even when DID patients switch between identities.

The different findings of this study and previous studies of priming in DID (Eich et al., 1997a, 1997b; Nissen et al., 1988; Peters et al., 1998) could be due to the higher power resulting from the larger sample in this study (31 patients tested with results pertaining to a mean of 24 patients reporting no recall for encoding phases). Further, we added measures of response times to index priming, whereas all previous studies on implicit memory performance in DID have relied only on accuracy scores. Response times may be a more sensitive measure of priming, as is indicated by our results on the impossible objects perceptual encoding task, where priming is indicating by response times but not by the proportions of correct object decisions. 
A third factor that may account for the different findings is that in all of the previous studies of implicit memory functioning in DID that obtained evidence of interidentity amnesia, explicit references were made to the studied stimulus material encoded by another identity. In the study by Peters et al. (1998), the test identity was instructed to complete word stems to words that had been learned by another identity. Eich et al. (1997b) presented a free recall task to the test identity of the words encoded by another identity immediately preceding the word stem completion task. In the study by Nissen et al. (1988), no direct reference was made to the studied material, but the task was performed in the context of other tasks that did. Explicit reference to the study phase and the material studied may have caused patients to misconceive the implicit memory task as an explicit measure of memory and to complete the task as such.

In the present study, however, no explicit reference was made to the studied material. Also, by incorporating a group of DID simulators, it was shown that whatever explicit knowledge was available in the test phase, it could not be put to use to influence implicit memory performance and simulate a pattern of interidentity amnesia. Simulators did differ from controls in the proportion of stem completions and the response times of the multipleword stem completion task; that is, they showed generally impaired performance both on studied and unstudied word stems. This may have been because they had to divide attention between role playing and performing the memory task. Importantly, however, priming scores of simulators were comparable to those of controls, indicating that task performance could not be influenced by strategies using explicit recollections of studied material, even after specific instructions regarding how to simulate interidentity amnesia in DID. This inability to simulate amnesia seemingly contrasts with findings in other studies using participants instructed to simulate amnesia (e.g., Davis et al., 1997; Eich et al., 1997a; Horton, Smith, Barghout, \& Connolly, 1992).

Our primary goal, however, in designing the memory tasks used in this study was not to detect but to exclude malingering. To this end we used a 1-week interval between the encoding and retrieval phases in the perceptual encoding task. Also, in all tasks, we instructed participants to react as fast as possible. This direction was given in the initial instruction and repeated after the practice trials. This instruction contrasts with instructions used in studies designed to detect malingering, in which no highspeed response instructions were given. We should note that in a word stem completion task performed by Davis et al. (1997), participants were instructed to immediately say aloud the first word that popped into mind and that would complete the word stem. However, given the mean response times of 2 to $4 \mathrm{sec}$ reported in this study, these instructions should not be considered high-speed instructions. Noteworthy is that when simulators in the present study were asked about their simulation strategy, they stated that they found it hard to simulate because they ei- ther felt they did not recognize any material from the study phase or that they did recognize material, but felt unable to simulate due to the time constraint. Note that it cannot be inferred that explicit memory traces were absent. It can, however, be concluded that whatever explicit knowledge was available in this study, it could not be put to use to influence implicit memory performance. Also note that it cannot be inferred whether patients have tried to simulate or not. It can only be said that had they tried to simulate interidentity amnesia, they would not have succeeded.

We replicated Vriezen et al. (1995) in demonstrating that the simple repetition of stimulus material at study and test was not a sufficient condition for priming. A priming effect was found on the related question, and no evidence of priming was found on the unrelated question. We obtained evidence of attribute-specific priming (i.e., when encoding and retrieval both pertained to sensory attributes). Conceptual priming thus seems to require the formation of domain-specific semantic representations. As noted by Vriezen et al., these findings of domain-specific priming call for a refinement of existing theoretical accounts of conceptual priming. Performance on conceptual priming tasks is not completely accounted for by the memory systems view because priming was not found on all tasks pertaining to a specific underlying memory system (i.e., the semantic memory system). Instead, memory performance appears to depend on both the involvement of the critical memory system and the overlap between encoding and retrieval processing operations. The observed domain-specific priming calls for the specification of the semantic memory system, characterized by attributespecific processing operations at encoding and retrieval (see also Cabeza, 1994). Domain-specific conceptual priming requires the specification of separate semantic memory subsystems characterized by either mainly sensory or mainly functional processing.

We replicated Schacter et al. (1990; Schacter et al., 1991; Schacter et al., 1992) and Cooper et al. (1992) by demonstrating evidence of perceptual priming selectively on possible objects when considering proportion of correct object decisions. Importantly, however, we extended their findings by demonstrating priming for both possible and impossible objects by including response times, a priming index they did not include. Because the task developed by Schacter et al. included novel, unfamiliar objects, perceptual priming was argued not to depend on, or reflect, the activation of preexisting memory representations, but rather to rely on the formation of new representations in the encoding phase (Schacter et al., 1990). They reasoned that the absence of priming for impossible objects was due to participants' inability to encode the three-dimensional object structure of impossible objects. However, the results of the present study show that it might be possible to form global mental representations of impossible objects. Priming of these representations may be visible only in the more sensitive priming measure of response times. Alternatively, priming of unfamiliar objects may be brought about by the repetition of lower level nodes of object char- 
acteristics. In that case, representations of unfamiliar objects that produce priming need not form a coherent, global, three-dimensional object structure, but instead need only consist of lower level representations formed in an earlier stage of information processing.

In conclusion, the main findings of the present study are that DID patients displayed normal implicit memory performance on both data-driven and conceptually driven tasks. These findings have theoretical significance for current views on memory dysfunction in DID. One possible implication is that amnesia for implicit information between the two identity states does not extend to neutrally valenced material, but, if it exists, is involved only in emotional information processing. This possibility seems to make sense given the etiology of DID as a pathological reaction to childhood trauma. In other words, the particular coping mechanisms that create identity-isolated implicit memory traces work only for information considered to be emotionally threatening or directly linked to past traumatic experiences. Future research thus should attempt to include trauma-related stimuli in implicit memory tests.

An alternative implication of the present results is that the presumed amnesic symptoms in DID never include implicit memory, whether emotionally significant or emotionally neutral, but are limited to explicit memory. In other words, the hypothesized coping mechanisms work to isolate conscious recollection of traumatic experiences but fail to prevent information transfer between identities at an implicit level. The present study does not bear on the distinction between explicit and implicit memory functioning, since we did not include an objective explicit memory task. However, in other work (Huntjens et al., 2001), we have obtained evidence of normal explicit memory performance in DID patients for neutral material, which argues against the possibility of amnesic symptoms being limited to explicit memory. What we did find in both our implicit and explicit memory studies was a dissociation between objective memory performance and patients' subjective reports; that is, although patients indicated no subjective recollection of the encoding phase performed by a different identity state at all, their test scores indicated normal memory functioning.

A third possible implication is thus that the reported amnesic symptoms in DID include neither implicit nor explicit memory, for either emotionally significant or emotionally neutral material. Instead, the reported amnesic symptoms are related to an identity's lack of subjective awareness of events experienced by another identity. Patients' subjective reports of interidentity amnesia may reflect their genuine phenomenological experiences, but their intact memory traces for an event may go without their being aware of ownership of that memory; that is, they suffer a lack of so-called meta-awareness. Dissociative amnesia thus may not be the correct term to describe perceived memory problems in DID (e.g., Read \& Lindsay, 2000). Instead, the presence of intact memory perfor- mance combined with the absence of memory metaawareness may be at the core of dissociative amnesia.

\section{REFERENCES}

American Psychiatric Association. (1994). Diagnostic and statistical manual of mental disorders (4th ed.). Washington, DC: Author. Baddeley, A. D., Wilson, B. A., \& WatTs, F. N. (1995). Handbook of memory disorders. Chichester, U.K.: Wiley.

Boon, S., \& DraiJer, N. (1993). Multiple personality disorder in The Netherlands: A clinical investigation of 71 patients. American Journal of Psychiatry, 150, 489-494.

Boon, S., \& DraIJER, N. (1994). Gestructureerd Klinisch Interview voor de vaststelling van DSM-IV Dissociatieve Stoornissen (SCID-D) [Structured Clinical Interview for the Diagnosis of DSM-IV Dissociative Disorders (SCID-D)]. Lisse: Swets \& Zeitlinger.

CABEZA, R (1994). A dissociation between two implicit conceptual tests supports the distinction between types of conceptual processing. Psychonomic Bulletin \& Review, 1, 505-508.

Carlson, E. B., \& Putnam, F. W. (1993). An update on the dissociative experience scale. Dissociation, 6, 16-27.

Chu, J. A., \& Dill, D. L. (1991). Dissociative symptoms in relation to childhood physical and sexual abuse. American Journal of Psychiatry, 147, 887-892.

Coons, P. M., Bowman, E. S., \& Milstein, V. (1988). Multiple personality disorder: A clinical investigation of 50 cases. Journal of Nervous \& Mental Disease, 176, 519-527.

Cooper, L. A., Schacter, D. L., Ballesteros, S., \& Moore, C. (1992). Priming and recognition of transformed three-dimensional objects: Effects of size and reflection. Journal of Experimental Psychology: Learning, Memory, \& Cognition, 18, 43-57.

Damasio, A. R. (1990). Category-related recognition defects as clues to the neural substrates of knowledge. Trends in Neurosciences, 13, 95-98.

Davis, H. P., King, J. H., Klebe, J. J., Bajszar, G., Bloodworth, M. R. \& WALLICK, S. L. (1997). The detection of simulated malingering using a computerized priming test. Archives of Clinical Neuropsychology, 12, 145-153.

Dick-Barnes, M., Nelson, R. O., \& Aine, C. J. (1987). Behavioral measures of multiple personality: The case of Margaret. Journal of Behavioral Therapy \& Experimental Psychiatry, 18, 229-239.

Dorahy, M. J. (2001). Dissociative identity disorder and memory dysfunction: The current state of experimental research, and its future directions. Clinical Psychology Review, 21, 771-795.

DraIJER, N., \& LANGELAND, W. (1999). Childhood trauma and perceived parental dysfunction in the etiology of dissociative symptoms in psychiatric inpatients. American Journal of Psychiatry, 156, 379-385.

Eich, E., Macaulay, D., Loewenstein, R. J., \& Dihle, P. H. (1997a). Implicit memory, interpersonality amnesia, and dissociative identity disorder: Comparing patients with simulators. In J. D. Read \& D. S. Lindsay (Eds.), Recollections of trauma: Scientific research and clinical practice (pp. 469-474). New York: Plenum.

Eich, E., Macaulay, D., Loewenstein, R. J., \& Dihle, P. H. (1997b). Memory, amnesia, and dissociative identity disorder. Psychological Science, 8, 417-422.

Gleaves, D. H., May, M. C., \& Cardeña, E. (2001). An examination of the diagnostic validity of dissociative identity disorder. Clinical Psychology Review, 21, 577-608.

Graf, P., SQuire, L. R., \& Mandler, G. (1984). The information that amnesic patients do not forget. Journal of Experimental Psychology: Learning, Memory, \& Cognition, 10, 164-178.

Horton, K. D., Smith, S. A., Barghout, N. K., \& Connolly, D. A. (1992). The use of indirect memory tests to assess malingered amnesia: A study of metamemory. Journal of Experimental Psychology: General, 121, 326-351.

Huntjens, R. J. C., Postma, A., Peters, M., Woertman, L., \& Van Der HART, O. (2001).Inter-identity amnesia for neutral, episodic information in Dissociative Identity Disorder. Manuscript submitted for publication. Lilienfeld, S. O., Lynn, S. J., Kirsch, I., Chaves, J. F., Sarbin, T. R., 
Ganaway, G. K., \& Powell, R. A. (1999). Dissociative identity disorder and the sociocognitive model: Recalling the lessons of the past. Psychological Bulletin, 125, 507-523.

Merckelbach, H., Muris, P., Schmidt, H., Rassin, E., \& HorselenBERG, R. (1998). De Creatieve Ervaringen Vragenlijst als maat voor "fantasy proneness" [The Creative Experiences Questionnaire (CEQ) as a measure of fantasy proneness]. De Psycholoog, 33, 204-208.

Nissen, M. J., Ross, J. L., Willingham, D. B., Mackenzie, T. B., \& Schacter, D. L. (1988). Memory and awareness in a patient with multiple personality disorder. Brain \& Cognition, 8, 117-134.

Patterson, K., \& Hodges, J. R. (1995). Disorders of semantic memory. In A. D. Baddeley, B. A. Wilson, \& F. N. Watts (Eds.), Handbook of memory disorders (pp. 167-186). Chichester, U.K.: Wiley.

Peters, M. L., Uyterlinde, S. A., Consemulder, J., \& Van der HART, O. (1998). Apparent amnesia on experimental memory tests in dissociative identity order: An exploratory study. Consciousness \& Cognition, 7, 27-41.

Putnam, F. W. (1995). Development of dissociative disorders. In D. Cicchetti \& D. J. Cohen (Eds.), Developmental psychopathology (Vol. 2, pp. 581-608). New York: Wiley.

Putnam, F. W. (1997). Dissociation in children and adolescents. New York: Guilford.

Putnam, F. W., Guroff, J. J., Silberman, E. K., Barban, E. K., \& Post, R. M. (1986). The clinical phenomenology of multiple personality disorder: 100 recent cases. Journal of Clinical Psychiatry, 47, 285-293.

READ, J. D., \& LindSAY, D. S. (2000). “Amnesia” for summer camps and high school graduation: Memory work increases reports of prior periods of remembering less. Journal of Traumatic Stress, 13, 129-147.

Roediger, H. L., III (1990). Implicit memory. American Psychologist, 45, 1043-1056.

Roediger, H. L., III, \& McDermott, K. B. (1993). Implicit memory in normal subjects. In F. Boller \& J. Grafman (Eds.), Handbook of neuropsychology (Vol. 8, pp. 63-131). Amsterdam: Elsevier.

Roediger, H. L., III, Weldon, M. S., \& Challis, B. H. (1989). Explaining dissociations between explicit and implicit measures of retention: A processing account. In H. L. Roediger III \& F. I. M. Craik (Eds.), Varieties of memory and consciousness: Essays in honour of Endel Tulving (pp. 3-41). Hillsdale, NJ: Erlbaum.

Ross, C. A., Miller, S. D., Reagor, P., Bjornson, L., Fraser, G. A., \& Anderson, G. (1990). Structured interview data on 102 cases of multiple personality disorder from four centers. American Journal of Psychiatry, 147, 596-601.

SCHACTER, D. L. (1987). Implicit memory: History and current status. Journal of Experimental Psychology: Learning, Memory, \& Cognition, 13, 501-518.
SCHACter, D. L. (1996). Searching for memory: The brain, the mind, and the past. New York: Basic Books.

Schacter,D. L., Cooper, L. A., \& Delaney, S. M. (1990). Implicit memory for unfamiliar objects depends on access to structural descriptions. Journal of Experimental Psychology: General, 119, 5-24.

Schacter, D. L., Cooper, L. A., Delaney, S. M., Peterson, M. A., \& Tharan, M. (1991). Implicit memory for possible and impossible objects: Constraints on the construction of structural descriptions. Journal of Experimental Psychology: Learning, Memory, \& Cognition, 17, 3-19.

Schacter, D. L., CoOper, L. A., \& VAldiserri, M. (1992). Implicit and explicit memory for novel visual objects in older and younger adults. Psychology \& Aging, 7, 299-308.

Schacter, D. L., \& Tulving, E. (1994). What are the memory systems of 1994? In D. L. Schacter \& E. Tulving (Eds.), Memory systems 1994 (pp. 1-38). Cambridge, MA: MIT Press.

Shimamura, A. P. (1986). Priming effects in amnesia: Evidence for a dissociable memory. Quarterly Journal of Experimental Psychology, 38A, 619-644.

Silberman, E. K., Putnam, F. W., Weingartner, H., Braun, B. G., \& Post, R. M. (1985). Dissociative states in multiple personality disorder. Psychiatry Research, 15, 153-160.

Spanos, N. P. (1996). Multiple identities and false memories: A sociocognitive perspective. Washington, DC: American Psychological Association.

SpIEgEL, D., \& CARdEÑA, E. (1991). Disintegrated experience: The dissociative disorders revisited. Journal of Abnormal Psychology, 100, 366-378

SQuire, L. R. (1986). Mechanisms of memory. Science, 232, 1612-1619.

Squire, L. R., Shimamura, A. P., \& Graf, P. (1987). Strength and duration of priming effects in normal subjects and amnesic patients. Neuropsychologia, 25, 195-210.

STEINBERG, M. M. D. (1993). Structured clinical interview for DSM-IV dissociative disorders (SCID-D). Washington, DC: American Psychiatric Press.

Verhage, F. (1964). Intelligentie en leeftijd: Onderzoek bij Nederlanders van twaalf tot zevenenzeventig jaar [Intelligence and age: Study with Dutch people from age 12 to 77]. Assen: Van Gorcum.

Vriezen, E. R., Moscovitch, M., \& Bellos, S. A. (1995). Priming effects in semantic classification tasks. Journal of Experimental Psychology: Learning, Memory, \& Cognition, 21, 933-946.

Warrington, E. K., \& Shallice, T. (1984). Category-specific semantic impairments. Brain, 107, 829-854.

(Manuscript received October 2, 2001; revision accepted for publication June 4, 2002.) 